\title{
OUTCOME OF SALINE WOUND LAVAGE PRIOR TO WOUND CLOSURE IN GYNAECOLOGICAL AND OBSTETRICAL PATIENTS
}

\author{
Uzma Saleem, Tayyaba Waseem*, Malik Waseem Babar* \\ Combined Military Hospital/National University of Medical Sciences (NUMS) Rawalpindi Pakistan, *Combined Military Hospital Zhob/National University of \\ Medical Sciences (NUMS) Pakistan
}

\section{ABSTRACT}

Objective: To determine the effectiveness of saline wound lavage in reducing wound infections in patients undergoing gynaecological and obstetrical abdominal surgical procedures.

Study Design: Quasi-experimental study.

Place and Duration of Study: Department of Obstetrics and Gynaecology, Pakistan Navy Ship Shifa Hospital, Karachi Pakistan, from Oct 2018 to Sep 2019.

Methodology: All the patients undergoing gynaecological or obstetrical surgical procedures were enrolled after informed consent. Participants underwent elective or emergency surgery. In Group A with 551 patients, saline wound Lavage was done before closure, whereas in 533 patients in group B saline wound irrigation was not done. Similar post-operative care was provided to both groups. All patients were observed for febrile illness and wound discharge on 2nd, 8th, 15th and 30th postoperative day.

Results: Out of 1084 patients, there were 551 (50.7\%) in saline wound irrigation group A, while 533 (49.3\%) were in group B where no saline wound irrigation was done. The frequency of febrile illness was observed in $49(3.8 \%)$ patients. Febrile illness was significantly higher in patients without saline wound irrigation as compared to patients with saline wound irrigation $(p$ value 0.002$)$. The frequency of wound discharge was observed in $28(22.2 \%)$ patients. Wound discharge was significantly higher in patients without saline wound irrigation as compared to patients with saline wound irrigation ( $p$-value $=0.018$ ).

Conclusion: Saline wound irrigation prior to wound closure in obstetrical and gynaecological abdominal procedures can lead to a significant reduction in surgical site infection.

Keywords: Febrile illness, Saline wound irrigation, Wound infection.

How to Cite This Article: Saleem U, Waseem T, Babar MW. Outcome of Saline Wound Lavage Prior To Wound Closure in Gynaecological and Obstetrical Patients. Pak Armed Forces Med J 2021; 71(6): 2070-2074. Doi: https://doi.org/10.51253/pafmj.v6i6.4952

\footnotetext{
This is an Open Access article distributed under the terms of the Creative Commons Attribution License (https://creativecommons.org/licenses/by-nc/4.0/), which permits unrestricted use, distribution, and reproduction in any medium, provided the original work is properly cited.
}

\section{INTRODUCTION}

Post-operative surgical site infection (SSI) is a major contributor towards post-operative morbidity and mortality, treatment cost and length of hospital stay. ${ }^{1,2}$ This results in substantial increase in economic hardships of health facilities. In Europe, they are one of commonest healthcare related infections. In Germany in 2016, 22.4\% of all infections were treatment related. ${ }^{3}$ This problem is especially aggravated in third world countries.

Incidence of primary and secondary cesarean section has increased substantially over last decades. Data from 169 countries which included $98.4 \%$ of the world's births, has shown that 29.7 million $(21.1 \%, 95 \%$ uncertainty interval 19.9-22.4) births took place via cesarean section in 2015, which was almost double the number of cesarean births in 2000 (160 million [12.1\%, 10.9-13.3] births). ${ }^{4}$ Rate of surgical site infection after

Correspondence: Dr Uzma Saleem, 26 Rumi Lane, Raja Akram Road, Rawalpindi Pakistan

Received: 08 Aug 2020; revision received: 08 Dec 2020; accepted: 10 Dec 2020 cesarean section is $13-15 \% .{ }^{4}$ In a third world country like Pakistan, significant rise in cesarean births from $2.7 \%$ in $1990-1991$ to $15.8 \%$ in $2012-2013$ has been reported. ${ }^{5}$ Hysterectomy is the commonest major gynaecological surgery among women of reproductive age, approximately 600,000 hysterectomies are annually performed in the United States. ${ }^{6}$ Exact rates of hysterectomy for benign indications is not known in Pakistan, however, majority of the procedures are performed via abdominal route. ${ }^{7}$ The ever rising rate of abdominal surgical procedures in gynecology and obstetrics calls for a search for simple and economical methods to minimize the burden of surgical site infections.

Many strategies have been advocated to lower the rate of surgical site infections. Saline wound irrigation is one of the more commonly used due to its safety and physiological composition. ${ }^{8}$ There has been a renewed interest in obtaining solid evidence regarding its efficacy or lack thereof. ${ }^{9}$ When executed properly, wound irrigation can help in wound healing from the inside 
tissue layers outward to the skin surface. It may also prevent premature surface healing over an abscess pocket or infected tract. The goal of irrigation is to clean the wound while avoiding trauma to wound bed and minimizing risk of introducing bacteria into wound bed. Evaluation of effects of saline irrigation before wound closure in decreasing surgical site infection is the topic of a systemic review and meta-analysis, whose protocol was published in $2018 .{ }^{10}$ We chose this topic for study, because wound infection is a significant cause of morbidity and rising cost of treatment in obstetrical and gynaecological patients.

\section{METHODOLOGY}

This quasi-experimental study was carried out at Department of Obstetrics \& Gynecology Pakistan Naval Ship Shifa Hospital Karachi, from October 2018 to September 2019. Approval was obtained from the Hospital Ethical committee of PNS SHIFA Karachi (via letter number ERC/2020/GYNAE/14). Informed consent was obtained from all patients.

Inclusion Criteria: Women undergoing abdominal surgeries or obstetrical procedures including elective and emergency cesarean section due to various reasons and gynecological surgeries like total abdominal hysterectomy, myomectomy, laparotomy for ectopic pregnancy and adnexal masses were included.

Exclusion Criteria: Women undergoing vaginal surgeries and emergency laparotomy for primary and secondary post-partum haemorrhage were excluded from the study.

Sample size was calculated by World Health Organisation (WHO) sample size calculator keeping 95\% confidence interval 5\% error and anticipated frequency $8 \% 11$, sample size was 459 but we included total of 1084 patients in the study by using non probability convenient sampling technique. In group A 551 patients underwent saline wound lavage prior to wound closure, whereas in group B consisting of 533 patients, saline wound irrigation was not performed. Most surgical procedures were performed via pfennensteil incision, occasionally lower midline incision was employed. All the patients received per-operative prophylactic antibiotic i.e. injection Ceftriaxone 1 gram intravenously, after test dose. In group A, after completion of intra peritoneal procedure, rectus sheath was sutured using Vicryl-1 running fashion. The wound was then irrigated with normal saline for 30 seconds and excess fluid was removed by mopping dry with abdominal sponge and suctioning using suction catheter. Group B did not undergo wound irrigation. In both groups, the subcutaneous tissue was sutured by 3-4 interrupted sutures using Vicryl-1. Skin closure was achieved either by using subcutaneous sutures using Prolene 1/ 0 . Antiseptic dressing was applied. All patients (group A \& B) were administered post-operative antibiotics injection Ceftriaxone $1 \mathrm{~g}$ IV twice a day. Injection metronidazole 500mg IV 8 hourly for 24 hours was added for those undergoing emergencies cesarean sections or myomectomy. Injection Toradol 30mg infusion was administered intravenously every 8 hours for first 24 hours during post op period for pain relief. In both groups, oral intake was encouraged after 8 to 24 hours depending upon the nature of surgery and presence of gut sounds. Foley's catheter was removed after 12 to 24 hours as per post-operative orders. All patients were prescribed tablet Mefenamic Acid 500mg every 8 hours once oral intake was established. Dressing was removed on 2nd post-operative day. Both the groups were observed for complications of febrile illness and wound discharge on 8th post op day and then on 15th and 30th post op day.

Febrile illness was defined as temperature $>380 \mathrm{C}$ 48 hours after surgery was considered as febrile illness while wound discharge was defined as any serous or pussy discharge from wound observed after 48 hours of surgery to 30th post-op day was considered as wound discharge.

Statistical analysis was carried out using Statistical Package for the social sciences (SPSS) version 23 Mean and Standard Deviation was calculated for quantitative variables like age, weight, height, BMI, duration of surgery and duration of hospital stay. Frequency and percentages were calculated for Pfannenstiel incision, use of cautery, suturing of subcutaneous tissue, and surgical procedure. Inferential statistics were explored by employing independent t-test and chi-square test. The $p$-value of $\leq 0.05$ was considered significant.

\section{RESULTS}

Of 1084 patients, the mean age was $36.64 \pm 5.08$ years while the mean duration of surgery was $63.96 \pm$ 11.61 minutes. Pfannenstiel incision was applied in $1056(97.4 \%)$ patients, use of cautery in 1060 (97.7\%) and suturing of subcutaneous tissue in 914 (84.3\%) patients. The most common surgical procedure was Elective LSCS 638 (57.5\%), followed by Emergency LSCS 382 (37.5\%), total abdominal hysterectomy 38 (3\%), laparotomy $14(1.1 \%)$, and myomectomy $12(.9 \%)$ patients. There were $651(50.7 \%)$ in saline wound irrigation group while $633(49.3 \%)$ in without saline wound irrigation. The non-significant difference of age 
( $p$-value 0.711$),$ weight ( $p$-value 0.955$),$ height ( $p$-value $0.978)$, BMI ( $p$-value 0.969$)$, duration of surgery ( $p$ value 0.593 ), duration of hospital stay ( $p$-value 0.848 ), Pfannenstiel incision ( $p$-value 0.851$)$, use of cautery ( $p$ value 0.865$)$, suturing of subcutaneous tissue ( $p$-value $0.779)$, and surgical procedure ( $p$-value 0.419$)$ were noted in between both groups (Table-I).

Table-I: Comparison of sociodemographic and clinical characteristics of the patients.

\begin{tabular}{|c|c|c|c|}
\hline \multirow[t]{2}{*}{ Variables } & $\begin{array}{c}\text { Group A } \\
(n=551)\end{array}$ & $\begin{array}{l}\text { Group B } \\
(n=533)\end{array}$ & \multirow{2}{*}{$\begin{array}{c}p- \\
\text { value }\end{array}$} \\
\hline & Mean \pm SD & Mean \pm SD & \\
\hline Age (years) & $36.58 \pm 5.21$ & $36.69 \pm 4.95$ & $0.711 a$ \\
\hline Weight (kg) & $60.13 \pm 5.11$ & $60.14 \pm 5.09$ & $0.955 a$ \\
\hline Height $(\mathrm{m})$ & $1.54 \pm 0.06$ & $1.53 \pm 0.05$ & $0.978 a$ \\
\hline BMI $\left(\mathrm{kg} / \mathrm{m}^{2}\right)$ & $28.28 \pm 3.98$ & $28.27 \pm 3.99$ & $0.969 a$ \\
\hline $\begin{array}{l}\text { Duration of surgery } \\
\text { (minutes) }\end{array}$ & $\begin{array}{c}63.96 \pm \\
11.61\end{array}$ & $\begin{array}{l}64.31 \pm \\
11.43\end{array}$ & $0.593 a$ \\
\hline \multirow[t]{2}{*}{$\begin{array}{l}\text { Duration of hospital } \\
\text { stay (days) }\end{array}$} & $2.63 \pm 0.48$ & $2.64 \pm 0.49$ & $0.848 a$ \\
\hline & n (\%) & n (\%) & \\
\hline Pfannenstiel incision & $532(50.3)$ & $524(49.6)$ & $0.851 ¥$ \\
\hline Use of cautery & $533(50.2)$ & $527(49.7)$ & $0.865 \not \geq$ \\
\hline $\begin{array}{l}\text { Suturing of } \\
\text { subcutaneous tissue }\end{array}$ & $472(51.6)$ & $442(48.3)$ & $0.779 ¥$ \\
\hline \multicolumn{4}{|l|}{ Surgical Procedure } \\
\hline Elective LSCS & $310(55.3)$ & $328(59.7)$ & \multirow{5}{*}{$0.419 ¥$} \\
\hline Emergency LSCS & $210(39.9)$ & $170(35.1)$ & \\
\hline Laparotomy & $6(0.9)$ & $8(1.3)$ & \\
\hline $\begin{array}{l}\text { Total Abdominal } \\
\text { Hysterectomy }\end{array}$ & $20(3.1)$ & $18(2.8)$ & \\
\hline Myomectomy & $5(0.8)$ & $7(1.1)$ & \\
\hline
\end{tabular}

The frequency of febrile illness was observed in $49(3.8 \%)$ patients. Febrile illness was significantly higher in patients without saline wound irrigation as compared to patients with saline wound irrigation ( $p$-value $0.002)$, The frequency of wound discharge was observed in $28(22.2 \%)$ patients. Wound discharge was significantly higher in patients without saline wound irrigation as compared to patients with saline wound irrigation ( $p$-value 0.018 ) shown in Table-II.

Table-II: Comparison of febrile illness and wound discharge in both groups.

\begin{tabular}{|c|c|c|c|}
\hline & $\begin{array}{c}\text { Group A } \\
(n=551)(\%)\end{array}$ & $\begin{array}{c}\text { Group B } \\
(n=533)(\%)\end{array}$ & $\begin{array}{c}p- \\
\text { value }\end{array}$ \\
\hline \multicolumn{4}{|c|}{ Febrile Illness } \\
\hline Yes & $13(2.3)$ & $36(6.7)$ & \multirow{2}{*}{0.002} \\
\hline No & $538(97.7)$ & $497(93.3)$ & \\
\hline \multicolumn{4}{|c|}{ Wound Discharge } \\
\hline Yes & $8(1.4)$ & $22(4.2)$ & \multirow{2}{*}{0.018} \\
\hline No & $543(98.6)$ & $511(95.8)$ & \\
\hline
\end{tabular}

\section{DISCUSSION}

There is a genuine need for well-designed clinical trials investigating surgical irrigation practices and evaluation of existing evidence to standardize irrigation practices. A meta-analysis has concluded that current published data are sufficient to support the elimination of antibiotic solutions and surfactants for surgical irrigation; and advocates the use of sterile normal saline, sterile water, and a medical device containing a sterile $0.05 \%$ chlorhexidine gluconate solution followed by sterile saline. ${ }^{9}$

The IOWISI (intra-operative wound irrigation to prevent surgical site infection after laparotomy) trial is a multicenter, randomized, double-blinded clinical trial registered in Germany in 2017. It studies three treatment groups, comparing IOWI (intra operative wound irrigation) with a $0.04 \%$ PHX (Antiseptic Polyhexanide) solution to no irrigation or saline irrigation before skin closure after laparotomy for visceral surgery (contamination level II-IV). The primary terminus of the trial is the surgical site infection rate within 30 days post-operatively. ${ }^{12}$

In a local study by Viqar and Afzal, 200 clean gynaecological and surgical cases were included. Half of them underwent saline irrigation whereas, the other half did not. They found that out of 100 patients whose wounds were washed with warm normal saline only 1 developed wound infection, while in the other group 8 patients had developed wound infection. ${ }^{11}$ These finding are comparable to our results.

A similar study was performed over a period of 2 years at Combined Military Hospital Chunian. intraoperative normal saline wound irrigation prior to wound closure was compared with simple wound closure without saline irrigation, for of development of surgical site infection in clean contaminated wounds. The observed surgical site infection rate in wound irrigation group was $4.5 \%$ while in the other group it was $10.2 \% .^{13}$ These statistically significant results $(p=0.004)$ are similar to our findings.

A cochrane review included one trial which compared rates of infection and healing in wounds cleansed with water and normal saline; three trials which compared cleansing with no cleansing and one trial which compared procaine spirit with water. ${ }^{14}$ Absence of a standard criteria for assessing wound infection across these trials limited the ability to pool the data. The major comparisons were water with normal saline and tap water with no cleansing. For chronic wounds, the relative risk of developing an infection when clean- 
sed with tap water compared with normal saline was 0.16, (95\% CI 0.01-2.96). Tap water was more effective than saline in reducing the infection rate in adults with acute wounds (RR 0.63, 95\% CI 0.40-0.99). The use of tap water to cleanse acute wounds in children was not associated with a statistically significant difference in infection when compared to saline (RR 1.07, 95\% CI $0.43-2.64) .{ }^{12}$ These findings do not agree with our results. It should be noted that unlike this review, our study only included surgical abdominal wounds.

A prospective randomized study was carried out by Güngördük and Asicioglu to examine the effect of saline wound irrigation before wound closure in the prevention of infection following caesarean delivery. Participants with indications for elective or emergency caesarean section were randomly allocated to 2 groups. A total of 260 women underwent wound irrigation before wound closure and 260 did not. No demographic differences were identified between the groups. There were also no significant differences between the groups in terms of factors known to influence wound infection. The incidence of wound infection was $7.3 \%$ for the control group and $6.5 \%$ for the saline group; however, the difference was not statistically significant ${ }^{15}$ $(p=0.86)$. Contrary to our findings, they concluded that saline wound irrigation before wound closure did not reduce the wound infection rates in patients undergoing caesarean delivery.

A prospective randomized study was carried out to evaluate whether saline irrigation decreases incidence of wound infection following abdominal gynaecological surgery.104 patients underwent wound irrigation before wound closure and 102 patients did not. There were no significant differences between the 2 groups in patient characteristics or in factors affecting the incidence of wound infection after abdominal gynecologic surgery. The incidence of wound infection was $10.6 \%$ among women who underwent wound irrigation and $9.8 \%$ among those who did not. This difference was not statistically significant. ${ }^{16}$ These results are contrary to our findings.

A prospective randomized study carried out in Turkey, examines the effectiveness of saline wound irrigation in reducing post-operative wound complications. Of 204 women undergoing primary cesarean sections were randomized, and 185 were included in the final analysis. There was no significant difference in terms of SSI rates between the two groups $(14.3 \%$ in the saline group vs $12.8 \%$ in the control group, $p=0.76$ ). Nonetheless, the occurrence of hematoma and seroma were significantly less in the saline irrigation group compared to the control group. ${ }^{17}$ These results do not support our findings.

A Comparative study done by Martinez Castano et al. between two groups addressed wound infection following laparotomy in neonates. In order to decrease wound infection at the culmination of the procedure the gloves, covertures and surgical instruments were changed and saline and antiseptic solutions were used during wound closure. It was noted that the group where these interventions were undertaken had lower infection rate i.e. $9 \%$ vs $58.3 \% .^{18}$. Although saline wound irrigation was only one of the multiple interventions, however, these results support its beneficial effects similar to our study.

\section{ACKNOWLEDGEMENT}

Authors acknowledge the assistance of Dr Asrar Ahmed and Mr Omair Adil.

\section{CONCLUSION}

The study concludes that saline wound irrigation prior to wound closure in obstetrical and gynaecological abdominal procedures can result in a notable reduction in surgical site infection. This simple, inexpensive and readily available intervention can go a long way in improving the outcomes of surgical procedures routinely performed in our practice. The inclusion of a variety of surgical procedures in the study, similarities in group characteristics and post-operative treatment are the strengths of the study. Inclusion of both clean and clean-contaminated cases in the study is a limiting feature, as it may have affected the results. Further studies are necessary to validate or refute the results of our study.

\section{Conflict of Interest: None.}

\section{Authors' Contribution}

US: Manuscript writing, TW \& MWB: Collection of data.

\section{REFERENCES}

1. Gelhorn HL, Anand SB, Parvizi J, Morrison T, Yu H, Pokrzywinski $R$, et al. Qualitative interviews to identify burden of illness, impacts and costs associated with surgical site infections. J Comp Eff Res 2018; 7(1): 357-367.

2. Zuarez-Easton S, Zafran N, Garmi G, Salim R. Post cesarean wound infection: prevalence, impact, prevention, and management challenges. Int J Womens Health 2017; 9(1): 81-88.

3. Behnke M, Aghdassi SJ, Hansen S, Diaz LAP, Gastmeier P, Piening $B$. The prevalence of nosocomial infection and antibiotic use in German hospitals. Dtsch Arztebl Int 2017; 114(2): 851-857.

4. Boerma T, Carine R, Dessalegn YM, Aluisio JD, Fernando CB, Liang J. Global epidemiology of use of and disparities in caesarean sections. Lancet 2018; 10155(4): 1341-1348.

5. Mumtaz S, Bahk J, Khang Y-H. Rising trends and inequalities in cesarean section rates in Pakistan: evidence from Pakistan demographic and health surveys, 1990-2013: PLoS ONE 2017; 12(10): e0186563.

6. James KC, Cara A, Robinson A, Ronald T, Burkman S. Hysterectomy. In: Women and Health 2nd ed: Elsevier BV 2013, Available at: DOI10.1016/b978-0-12-384978-6.00027-3 


\section{Saline Wound Lavage Prior}

7. Irum N, Ashraf M, Zaiba S, Majeed A. An analysis of complications and indications of hysterectomy between scarred and unscarred uterus. Ann Pak Inst Med Sci2012; 8(3): 187-190.

8. Gabriel A, Schraga ED. Wound irrigation; drugs \& diseases: clinical procedures. 2017 [Internet] Available at: https://emedicine.medscape.com/article/1895071-overview (Accessed on December 12, 2019)

9. Barnes S, Spencer M, Graham D, Johnson HB. Surgical wound irrigation: a call for evidence-based standardization of practice. Am J Infect Control 2014; 42(5): 525-529.

10. Pieper D, Rombey T, Doerner J, Rembe J, Zirngibl H, Zarras K, et al. The role of saline irrigation prior to wound closure in the reduction of surgical site infection: protocol for a systematic review and meta-analysis. Syst Rev 2018; 7(1): 152.

11. Viqar A. The efficacy of normal saline irrigation to prevent surgical site infection. Pak Armed Forces Med J 2018; 65(1): 13-15.

12. Mueller TC, Nitsche U, Kehl V, Schirren R, Schossow B, Goess R, et al IOWISI Study Group. Intraoperative wound irrigation to prevent surgical site infection after laparotomy (IOWISI): study protocol for a randomized controlled trial. Trials 2017; 18(1): 410.
13. Khan R, Asghar M, Siyar F, Saleem M, Safdar MH. Role of peroperative wound irrigation in prophylaxis of surgical site infection in clean contaminated wounds. Pak Armed Forces Med J 2019; 69(1): 60-64.

14. Fernandez R, Griffiths R. Water for wound cleansing. Cochrane Database Syst Rev 2012; 15(2): CD003861.

15. Güngördük K, Asicioglu O, Celikkol O, Ark C, Tekırdağ AI. Does saline irrigation reduce the wound infection in caesarean delivery? J Obstet Gynaecol 2010; 30(7): 662-666.

16. Al-Ramahi M, Bata M, Sumreen I, Amr M. Saline irrigation and wound infection in abdominal gynecologic surgery. Int J Gynaecol Obstet. 2006; 94(1): 33-36.

17. Aslan Çetin B, Aydogan Mathyk B, Barut S, Koroglu N, Zindar $\mathrm{Y}$, Konal M, et al. The impact of subcutaneous irrigation on wound complications after cesarean sections: A prospective randomised study. Eur J Obstet Gynecol Reprod Biol 2018; 227(1): 67-70.

18. Castaño I, García MJ, Morote J, Pruneda R, Ibieta M, Ticona J, et al. Prevention of the wound infection: little changes, huge results. Cirugia Pediatr 2017; 30(1): 138-141. 